\title{
STRAY BULLET A DILEMA:
}

\section{A CASE REPORT OF A 06 YEAR OLD BOY}

\author{
Dr. Ghulam Yasin, Prof. Dr. Ghulam Mustafa Arain
}

Article Citation

Yasin G, Arain GM. Stray bullet a dilema: a case report of a 06 year old boy. Professional Med J 2013;20(2): 000-000.

\section{INTRODUCTION}

Use of weapons and aggression has increased in last decade. This has lead to increased number of victims injured or lost life by stray bullets to the extent that sense of insecurity has further affected the community ${ }^{1}$. Stray bullets remind us of the fact that there are bullets flying in our communities almost every day.

Stray bullet injury is defined as bullet injury leading to injury or loss of life not intended or targeted at victim. In $81.4 \%$ of cases victim is even unaware of any shooting incidence ${ }^{2,3}$.

In overall, international data shows $20.5 \%$ death rate of victim's .Males are 55.5\% while females are $44.5 \%$. About $31.5 \%$ victims are from $1-14$ years of age. This incidence in children is quite high ${ }^{3}$.

As regards anatomical site $35 \%$ extremity is injured, $30 \%$ abdomen \& torso and $20.5 \%$ head, face \& neck $k^{4,5}$.

\section{History \& Clinical Examination}

Our patient Master Shehbaz Khan S/O Mr Abdul Aziz six year of age (Fig 1), lonely brother of six sister's resident of Chabrai Bala D G Khan was standing in his grandparents' house, where his family had gathered to participate in marriage function. The patient was brought by relatives and informed the parents that he suffered from some pointing injury like iron rod to his right cheek and lost one tooth. He was managed locally with dressing and pain killer medicine. After some days parents felt swelling in his left cheek which was pain full considering it as broken tooth stuck in the cheek.

After a period of 18 days they consulted us for the painful swelling. On clinical examination there was bruised entry point at right submandibular area, near body of mandible (Fig2). Another bruised area with tender swelling in left cheek against second premolar teeth was noted (Fig 3). Second premolar tooth was partially broken Fig (4). The swelling was bimanually palpable. Rest of oral cavity was normal. X-ray depicted it as a bullet. When this was disclosed to the parents they totally refused for that, how it is possible? However they agreed for surgery, all the relatives especially the allegated persons accompanied. The patient was investigated and prepared for surgery under General Anesthesia. The bullet was extracted from inside, (Fig 5) wound stitched in layers with catgut $3 / 0$ and bullet handed over to the parents (Fig 6 ). They were strongly astonished. At follow up patient was alright but it created a social problem in the family that they directly fired on our kid and misguided / deceived us. This was discussed with all and solved the matter that it was an accidental / stray bullet.

\section{DISCUSSION}

Victims of stray bullets are essentially 'collateral damage' and are usually disconnected from the events that lead to their injury or death, they are innocent by standers who typically have no opportunity to flee or take any other preventive measures ${ }^{6}$. 


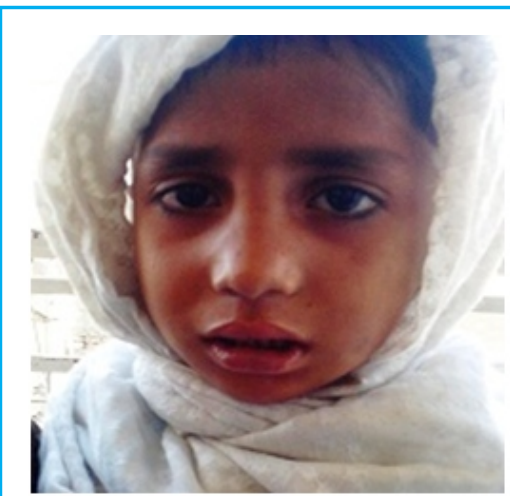

Fig-1,

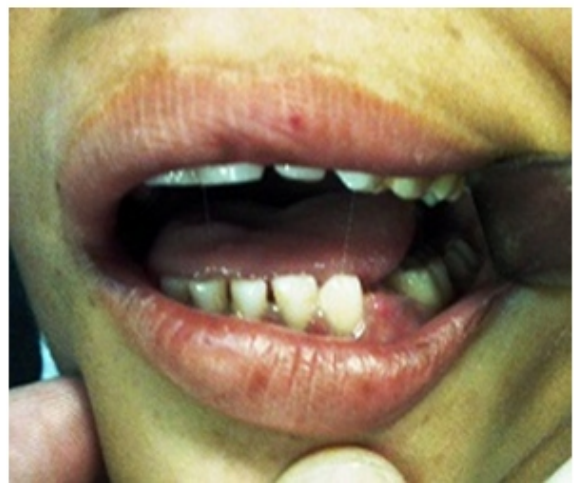

Fig-4.

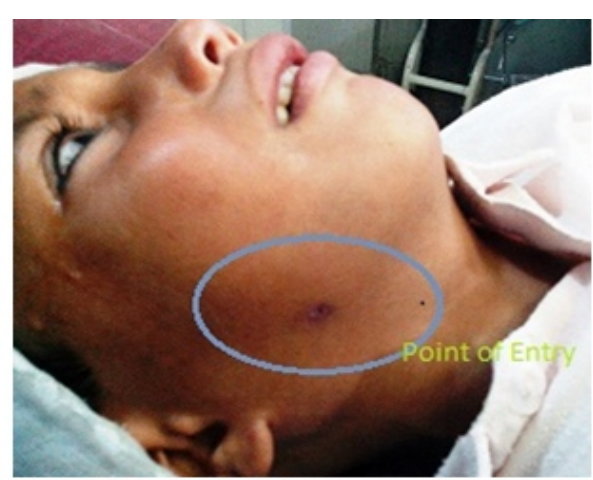

Fig-2.

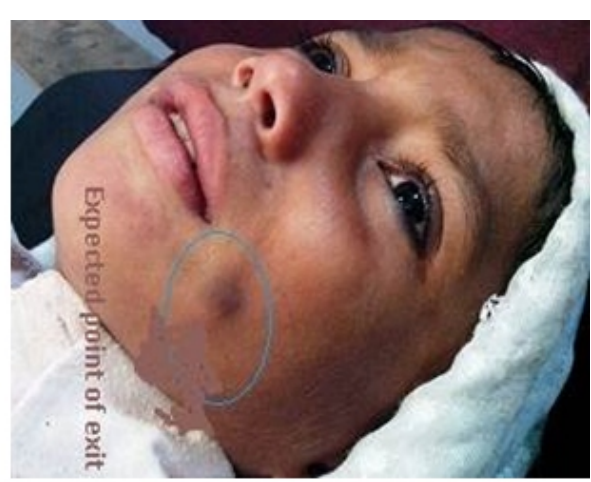

Fig-3.

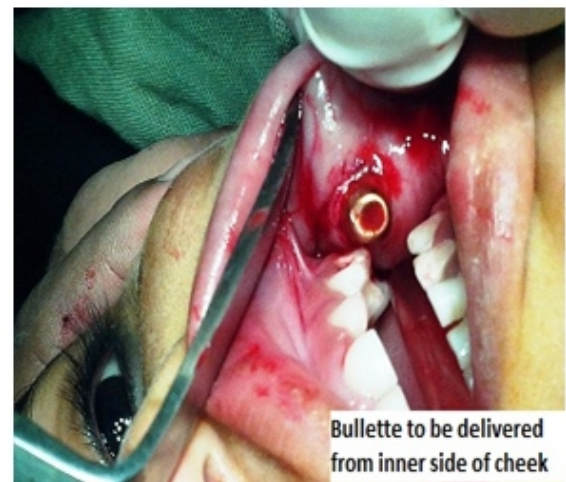

Fig-5.

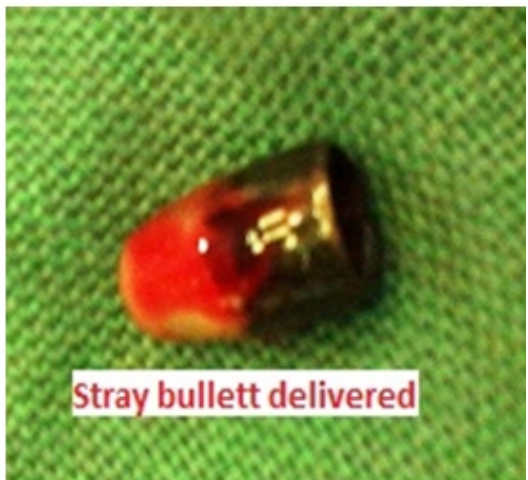

Fig-6.
"Stray-bullet shootings alter the nature of life in many ways, creating fear and anxiety in the community and prompting parents to keep children indoors and take other precautions. Incidence is more at weekends, sports \& hunting, celebrations (i.e. wedding, New Year's night and other holidays), maintenance \& handling of weapons \& incidental violence ${ }^{7}$.

To overcome the problem, we have to expand the preventive measures, such as "hot-spot policing," which involves increasing enforcement of firearm laws in areas with high level of gun violence.

Rules have to be made and implemented strictly. Weapon licenses, show off \& celebrating gun fire can easily be controlled by involving local authorities and public representatives. Unrest of population controlled by increasing employment opportunity, improving economics and improving our foreign relation will decrease aggression and weapon handling and they decrease stray bullet injury also.

I am passionate about the issue and would love to change some misperceptions and the culture of gun fire violence in Pakistan.

\section{Copyright@ 10 Mar, 2013.}

\section{REFERENCES}

1. Wani AA, Ramzan AU, Shoib $Y$, et al. Stray bullet: an accidental killer during riot control. Surg Neurol Int. 2011;2:122.

2. Karch DL, Logan J, Patel N; Centers for Disease Control and Prevention (CDC). Surveillance for violent deaths V National Violent Death Reporting System, 16 states, 2008. MMWR Surveill Summ. 2011;60:1Y49. J Trauma Acute Care Surg.

3. Akhtar J, Ahmed S, SoomroMA, Zamir N, Sharif A. Stray bullet injuries in children: an alert for the physicians. J Coll 
Physicians Surg Pak. 2006;16:738Y739.

4. Qureshi AU, Akhtar S, Gondal KM. Stray bullet in inferior vena cava. J Coll Physicians Surg Pak. 2010;20:414Y415.

5. Martucciello G, Tripodi R. A stray bullet to the brain. Lancet.2012;379:e19.
6. HussainM, Bari E. Intracerebralmigration of stray bullet leading to sudden and fatal worsening. J Coll Physicians Surg Pak. 2011;21:182Y183.

7. Cantu B. 1 injured from random gunfire celebrating New Year in Dallas. Dallas Morning News. 2009 Jan 2. Available at: http://www. dentonrc.com/sharedcontent/dws/dn/ latestnews/stories/010109dnmet.2fd8f6ae.html\# . Accessed February 25, 2011.

\section{AUTHOR(S):}

1. DR. GHULAM YASIN

Senior Surgeon

Department of General Surgery,

Dera Ghazi Khan Medical College, D.G. Khan
Correspondence Address:

\section{Dr. Ghulam Yasin}

28-D CPC Colony Atomic Energy

Dera Ghazi Khan

drgyaseen@gmail.com

2. PROF. DR. GHULAM MUSTAFA ARAIN

Professor of Surgery

Department of General Surgery,

Dera Ghazi Khan Medical College, D.G. Khan

Article received on: 26/02/2013 Accepted for Publication: 10/03/2013 Received after proof reading: 20/03/2013 